\title{
Glomerular Filtration Rate Following Pediatric Liver Transplantation-The SPLIT Experience
}

\author{
K. Campbella, V. Ng ${ }^{\mathrm{b}}$, S. Martin ${ }^{\mathrm{c}}$, J. Mageed, \\ J. Goebel ${ }^{a}$, R. Anand ${ }^{\mathrm{e}}$, K. Martz ${ }^{\mathrm{e}}$, J. Bucuvalase \\ and the SPLIT Renal Function Working Group \\ a Cincinnati Children's Hospital Medical Center, Cincinnati, \\ $\mathrm{OH}$ \\ b The Hospital for Sick Children, Toronto, Canada \\ ${ }^{c}$ CHU Sainte-Justine, Montreal, Canada \\ 'University of Michigan Health System, Ann Arbor, MI \\ e The EMMES Corporation, Rockville, MD \\ Supported by National Institutes of Health (U01 \\ DK061693-01A1). Additional support provided by Astellas \\ Pharma US, Inc, and Roche Laboratories. \\ Corresponding author: Kathleen M. Campbell, \\ Kathleen.campbell@cchmc.org
}

Impaired kidney function is a well-recognized complication following liver transplantation (LT). Studies of this complication in children have been limited by small numbers and insensitive outcome measures. Our aim was to define the prevalence of, and identify risk factors for, post-LT kidney dysfunction in a multicenter pediatric cohort using measured glomerular filtration rate (mGFR). We conducted a crosssectional study of 397 patients enrolled in the Studies in Pediatric Liver Transplantation (SPLIT) registry, using $\mathrm{mGFR}<90 \mathrm{~mL} / \mathrm{min} / 1.73 \mathrm{~m}^{2}$ as the primary outcome measure. Median age at LT was 2.2 years. Primary diagnoses were biliary atresia $(44.6 \%)$, fulminant liver failure $(\mathbf{9 . 8 \%})$, metabolic liver disease $(16.4 \%)$, chronic cholestatic liver disease $(13.1 \%)$, cryptogenic cirrhosis $(4.3 \%)$ and other $(11.8 \%)$. At a mean of 5.2 years post-LT, $17.6 \%$ of patients had a mGFR < $90 \mathrm{~mL} / \mathrm{min} / 1.73 \mathrm{~m}^{2}$. In univariate analysis, factors associated with this outcome were transplant center, age at LT, primary diagnosis, calculated GFR (cGFR) at LT and 12 months post-LT, primary immunosuppression, early post-LT kidney complications, age at mGFR, height and weight Z-scores at 12 months post-LT. In multivariate analysis, independent variables associated with a mGFR $<90 \mathrm{~mL} / \mathrm{min} / 1.73 \mathrm{~m}^{2}$ were primary immunosuppression, age at LT, cGFR at LT and height Z-score at 12 months post-LT.

Key words: glomerular filtration rate, multicenter studies, pediatric liver transplantation, long-term outcomes, renal dysfunction

Abbreviations: CKD, chronic kidney disease; cGFR, calculated glomerular filtration rate; KDOQI, Kidney Disease Outcomes Quality Initiative; LT, liver transplanta- tion; mGFR, measured glomerular filtration rate; PELD, Pediatric End Stage Liver Disease; SPLIT, Studies in Pediatric Liver Transplantation.

Received 2 March 2010, revised 2 September 2010 and accepted for publication 15 September 2010

\section{Introduction}

Introduction of the calcineurin inhibitors cyclosporine and tacrolimus revolutionized solid organ transplantation by decreasing acute allograft rejection and early graft loss, and increasing patient and graft survival. However, as long-term posttransplant survival has improved, adverse effects associated with the chronic use of these medications have emerged, among them, the risk of chronic nephrotoxicity, which leads to kidney dysfunction in almost one-third and to chronic kidney disease in up to $21 \%$ of all solid organ transplant recipients (1-10). In LT recipients in particular, the risk of chronic kidney disease in adults is up to $18 \%$ by 13 years posttransplant (11). The morbidity and mortality of this complication in pediatric transplant recipients are potentially greater than those described in adults, as children have a longer life span following transplantation with greater cumulative exposure to the calcineurin inhibitors and other nephrotoxic drugs (12-14). In addition, the impact on kidney function of physiologic changes associated with pubertal growth and development in this population is unknown. These changes may accelerate the progression of calcineurin inhibitor induced nephrotoxicity as has been noted in other chronic nephropathies (15-18).

One of the goals of long-term posttransplant management is to prevent or delay the onset of late complications, such as chronic kidney dysfunction. In order to accomplish this goal, we must identify those at risk, define contributing factors, and develop strategies for intervention. A thorough examination of the clinical and biochemical risk factors, and the impact of proposed interventions in pediatric transplant patients has been hampered by the limitations and biases associated with small populations, single centers, and variable and insensitive outcome measures. This has resulted in conflicting reports regarding prevalence, risk factors, timing and progression of posttransplant kidney dysfunction in children (19-28). 


\section{Campbell et al.}

Table 1: Method of measured GFR for each study center

\begin{tabular}{|c|c|c|}
\hline Center & Radionuclide & Sampling and calculation \\
\hline $\bar{A}$ & Single injection DTPA & Sampling at 2, 2.5, 3 and $3.5 \mathrm{~h}$, single compartment model \\
\hline $\mathrm{B}$ & Single injection DTPA & Sampling at $2 \mathrm{~h}$, external skull clearance \\
\hline C & Single injection DTPA & Sampling at 2, 3 and 4 h, 2 compartment model \\
\hline $\mathrm{D}$ & Single injection DTPA & Sampling at 1.5 and $2.5 \mathrm{~h}$ \\
\hline $\mathrm{E}$ & $\begin{array}{l}\text { Single injection } \\
\quad \text { (subcutaneous) lothalamate }\end{array}$ & Plasma and urine sampling at 1 and $2 \mathrm{~h}$ \\
\hline $\mathrm{F}$ & Single injection DTPA & $\begin{array}{l}<50 \mathrm{~kg} \text {-sampling at } 1,2 \text { and } 3 \mathrm{~h}>50 \mathrm{~kg} \text {-sampling at 2,3 } \\
\text { and } 4 \mathrm{~h} \text {, single compartment model }\end{array}$ \\
\hline G & Single injection DTPA & Sampling at $0,1.5,2,2.5$ and $3 \mathrm{~h}$ \\
\hline $\mathrm{H}$ & Single injection lothalamate & Sampling at 5, 10, $30 \mathrm{~min}, 1,2,3$ and $4 \mathrm{~h}, 2$ compartment model \\
\hline I & Single injection DTPA & Sampling at 2, 3 and $4 \mathrm{~h}$, single compartment model \\
\hline
\end{tabular}

In this multicenter study of pediatric $L T$ recipients, we have employed the Studies in Pediatric Liver Transplantation (SPLIT) database to define the prevalence of post-LT kidney impairment using the gold standard for kidney functional assessment, mGFR (29). In addition, we have used this robust clinical database to identify variables associated with the development of kidney dysfunction in this population. The work done here will serve as a foundation for clinical trials and/or comparative effectiveness analyses focusing on strategies to optimize kidney function in future and current post-LT patients.

\section{Patients and Methods}

\section{Patients}

This cross-sectional study is a component of the larger SPLIT prospective database, which has been approved by the Institutional Review Boards of all involved institutions, and inclusion in which requires written informed consent by the parent/guardian. Clinical data submitted to SPLIT are collected prospectively from the time of transplant listing, with individual reports designed to capture key events such as transplant, rejection, infection and other discrete posttransplant complications.

Patient inclusion criteria for this analysis were enrollment in SPLIT, time since $L T \geq 300$ days, and mGFR completed as part of standard posttransplant clinical care. Exclusion criteria included previous LT predating SPLIT enrollment, receipt of nonhepatic solid organ transplant, only available mGFR obtained $<300$ days post-LT. Data were retrieved from the SPLIT database and, when possible, missing data were captured by targeted chart review at individual centers.

\section{GFR and Z-score measurements}

All $\mathrm{mGFRs}$ are expressed as $\mathrm{mL} / \mathrm{min} / 1.73 \mathrm{~m}^{2}$ and were completed via radionuclide clearance technique in nonacutely ill posttransplant outpatients as a component of standard clinical care. The specific methods employed at each of the centers are presented in Table 1. The primary outcome measure, kidney dysfunction, was defined as a mGFR $<90 \mathrm{~mL} / \mathrm{min} / 1.73 \mathrm{~m}^{2}$ corresponding to stage 2 or greater chronic kidney disease as defined by the National Kidney Foundation Kidney Disease Outcomes Quality Initiative (KDOQI) (30). Calculated GFRs were obtained using the Schwartz formula (31). Standardized weight and height Z-scores were calculated by reference to age-specific and sex-specific charts for the normal population, as provided by the Centers for Disease Control (http://www.cdc.gov/growthcharts/) (32).

\section{Statistical analysis}

In the univariate analysis, independent variables including demographic characteristics and clinical characteristics collected at LT, 30 days postLT, 12 months post-LT and at mGFR follow-up were compared between patients with a $\mathrm{mGFR}<90 \mathrm{~mL} / \mathrm{min} / 1.73 \mathrm{~m}^{2}$ and those with a $\mathrm{mGFR} \geq$ $90 \mathrm{~mL} / \mathrm{min} / 1.73 \mathrm{~m}^{2}$. The Pearson chi-square test was used to compare categorical variables and the Wilcoxon rank sum test was used for continuous variables. Independent variables with a p-value $<0.10$ in the univariate analysis were included in the multivariable logistic regression model. Model reduction was performed using the backward elimination method, and factors remaining significant at a $p$-value $\leq 0.05$ were maintained in the final model. As a secondary analysis, a generalized linear mixed-effects model was created to control for possible center effect. To investigate the possibility of selection bias at the participating centers, basic demographic and clinical variables were compared between our study population $(N=397)$ and the population of mGFR-eligible patients seen at participating centers over the same time period and meeting center-specific criteria for mGFR screening, but who did not have a mGFR completed $(N=198)$. All statistical analyses were performed using the SAS System for Windows version 8.02 or higher (SAS Institute, Cary, NC, USA).

\section{Results}

\section{Patient characteristics}

We identified 397 patients from nine North American transplant centers who met inclusion criteria, and who had a mGFR completed between July 2003 and December 2008. These patients comprise the study group. When compared to the mGFR-eligible SPLIT cohort ( $N=198$ ), the study population included more males $(50.1 \%$ vs. $39.4 \%$, $\mathrm{p}=0.013)$, more Caucasian patients $(72.8 \%$ vs. $58.6 \%$, $\mathrm{p}=0.022$ ), and more patients transplanted before 2000 (32\% vs. 21.2\%, $p=0.02$ ). There were no differences between the study cohort and the mGFR eligible cohort with regard to distribution of age at LT, primary diagnosis, calculated PELD score at LT, calculated GFR at LT, or base immunosuppression at 30 days and 12 months post-LT.

The distribution of mGFRs by transplant center is shown in Figure 1. At a mean of 5.2 years post-LT, $17.6 \%$ of patients had a $\mathrm{mGFR}<90 \mathrm{~mL} / \mathrm{min} / 1.73 \mathrm{~m}^{2}$. Based on the National Kidney Foundation Classification of Chronic Kidney Disease (CKD), 14.6\% have stage 2 CKD (GFR 60-89), $2.5 \%$ have stage 3 CKD (GFR 30-59) and 0.5\% have stage 4-5 CKD (GFR < 30) (Figure 2). 


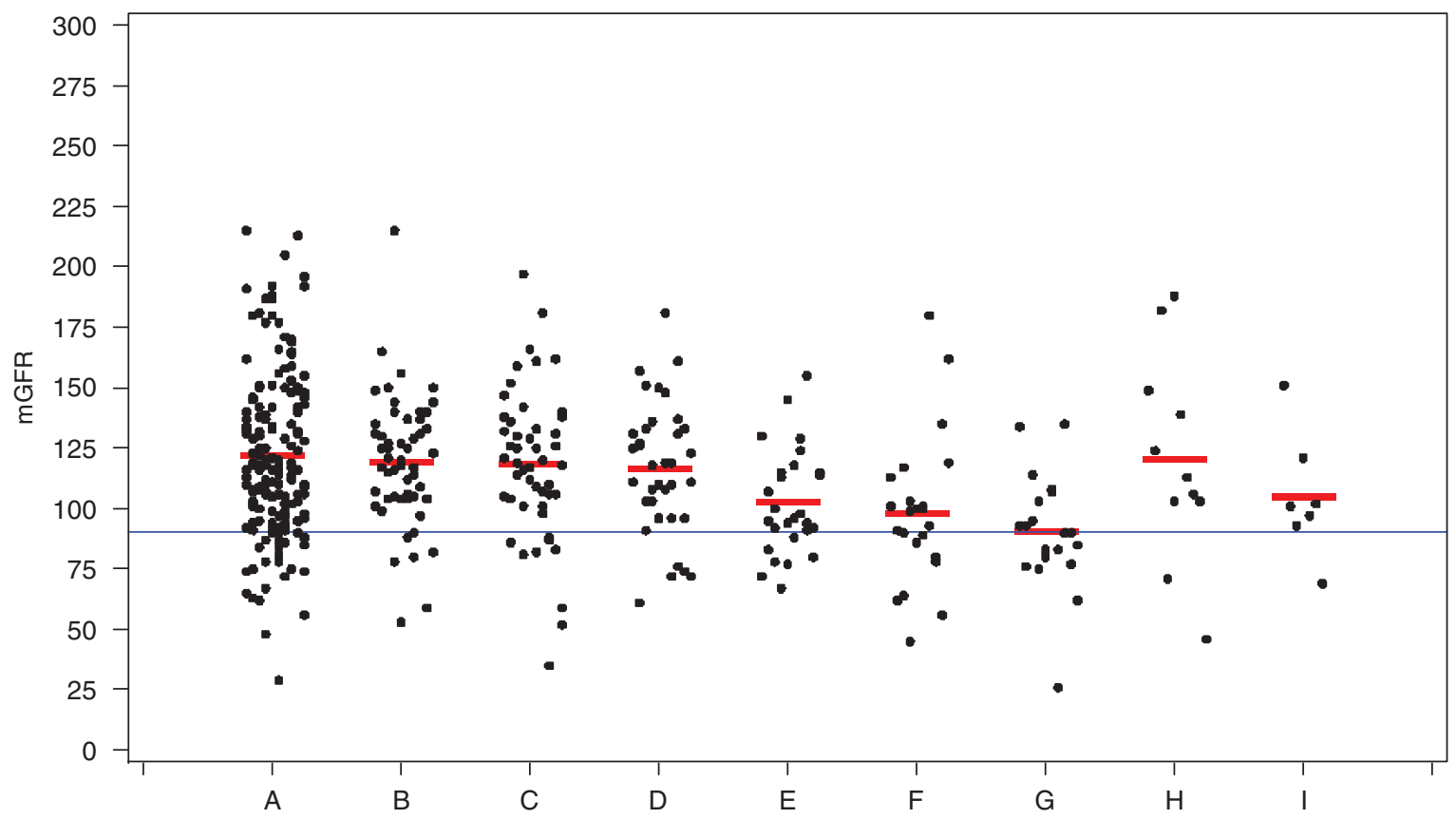

Figure 1: Distribution of mGFRs by transplant center (with means).

Forty-four patients (11.1\%) had a calculated GFR $<90 \mathrm{~mL} / \mathrm{min} / 1.73 \mathrm{~m}^{2}$ at the time of LT. Of these, the majority $(70.5 \%)$ had an improvement in GFR with time; only $29.5 \%(N=13)$ had evidence of kidney dysfunction at follow-up. Of the patients with a calculated GFR $\geq 90 \mathrm{~mL} / \mathrm{min} / 1.73 \mathrm{~m}^{2}$ at LT, 15.6\% ( $\left.\mathrm{N}=52\right)$ had kidney dysfunction at follow-up (Figure 3 ).
Figure 4 presents the mGFR along with the cGFR from the same visit, and illustrates the relationship between these two measures of kidney function in our population.

\section{Univariate analysis}

Twelve month post-LT characteristics were included as independent variables in the univariate analysis. For this

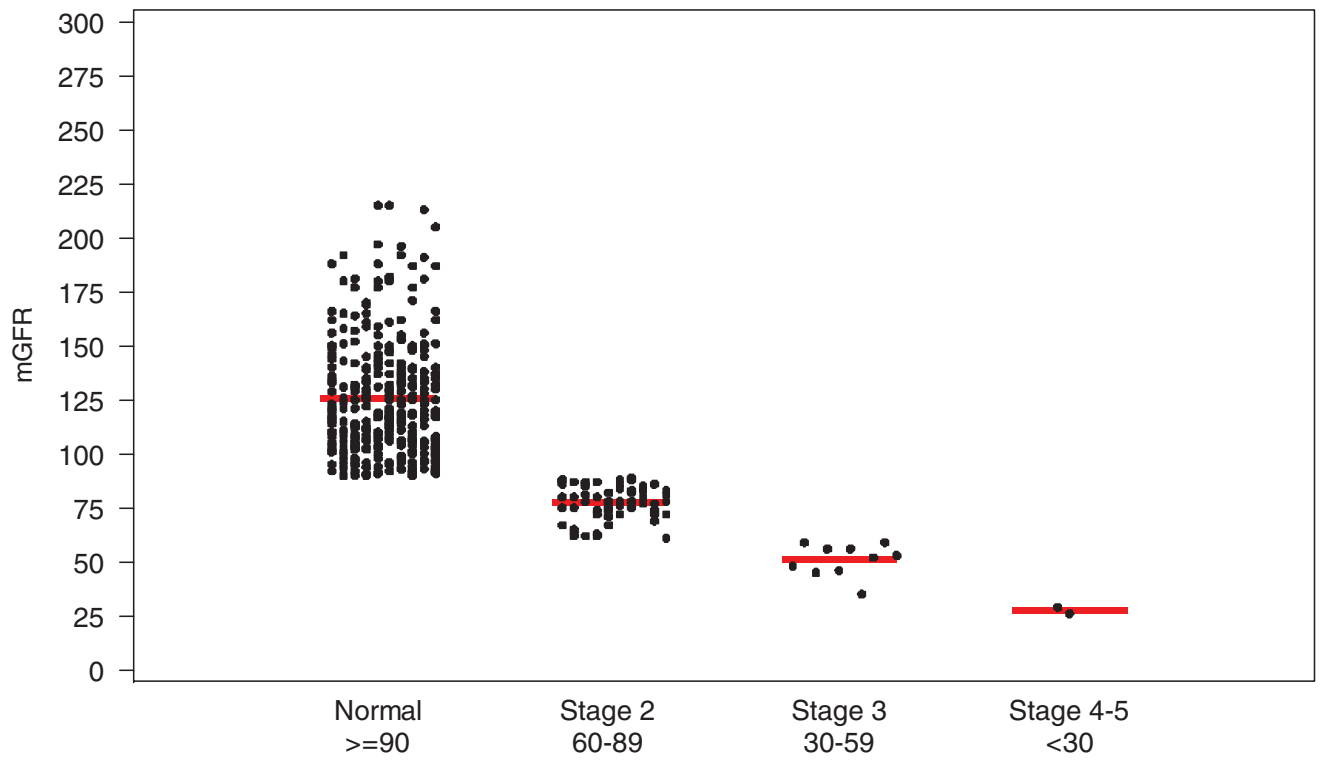

Figure 2: Distribution of mGFRs by CKD stage (with means). 


\section{Campbell et al.}

cGFR $<90 \mathrm{ml} / \mathrm{min} / 1.73 \mathrm{~m}^{2}$ at LT

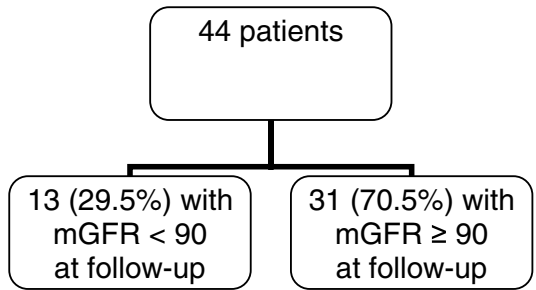

CGFR $\geq 90 \mathrm{ml} / \mathrm{min} / 1.73 \mathrm{~m}^{2}$ at $\mathrm{LT}$

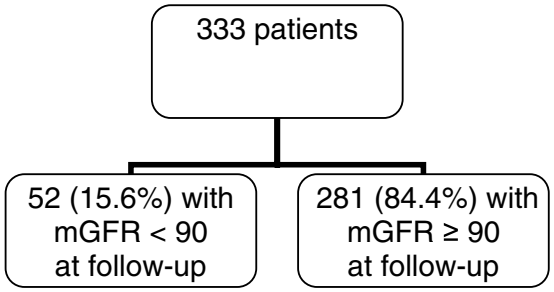

Figure 3: mGFR at post-LT followup by cGFR at LT. reason, the 70 patients whose mGFR was completed at their 12-month follow-up visit, or for whom 12-month information was unavailable, were excluded from analysis, bringing the sample size to 327 (Table 2).

Variables associated with a $\mathrm{mGFR}<90 \mathrm{~mL} / \mathrm{min} / 1.73 \mathrm{~m}^{2}$ included transplant center, older age at LT, primary diagnosis, cGFR $<90 \mathrm{~mL} / \mathrm{min} / 1.73 \mathrm{~m}^{2}$ at LT and at 12 months post-LT, cyclosporine immunosuppression at 30 days and 12 months post-LT, kidney complications in the first 30 days post-LT, lower height and weight Z-score at 12 months post-LT and age $\geq 13$ years at follow-up. Other independent variables, including race, sex and time since $L T$, did not differ significantly between groups.

\section{Multivariate analysis}

As we were interested in identifying early factors associated with long-term posttransplant kidney dysfunction, the multivariate analysis did not include clinical information collected at the time of the mGFR visit, with the exception of age at follow-up ( $<13$ years, $\geq 13$ years), which was used as a surrogate marker of pubertal status. All other variables with a $p$-value $\leq 0.10$ were included in the logistic regression model. Patients with incomplete data sets were excluded, leaving 289 patients.

In the multivariate analysis, four factors were identified as being independently associated with a mGFR < $90 \mathrm{~mL} / \mathrm{min} / 1.73 \mathrm{~m}^{2}$ at last follow-up (Table 3): transplant

\section{Measured GFR and Calculated GFR}

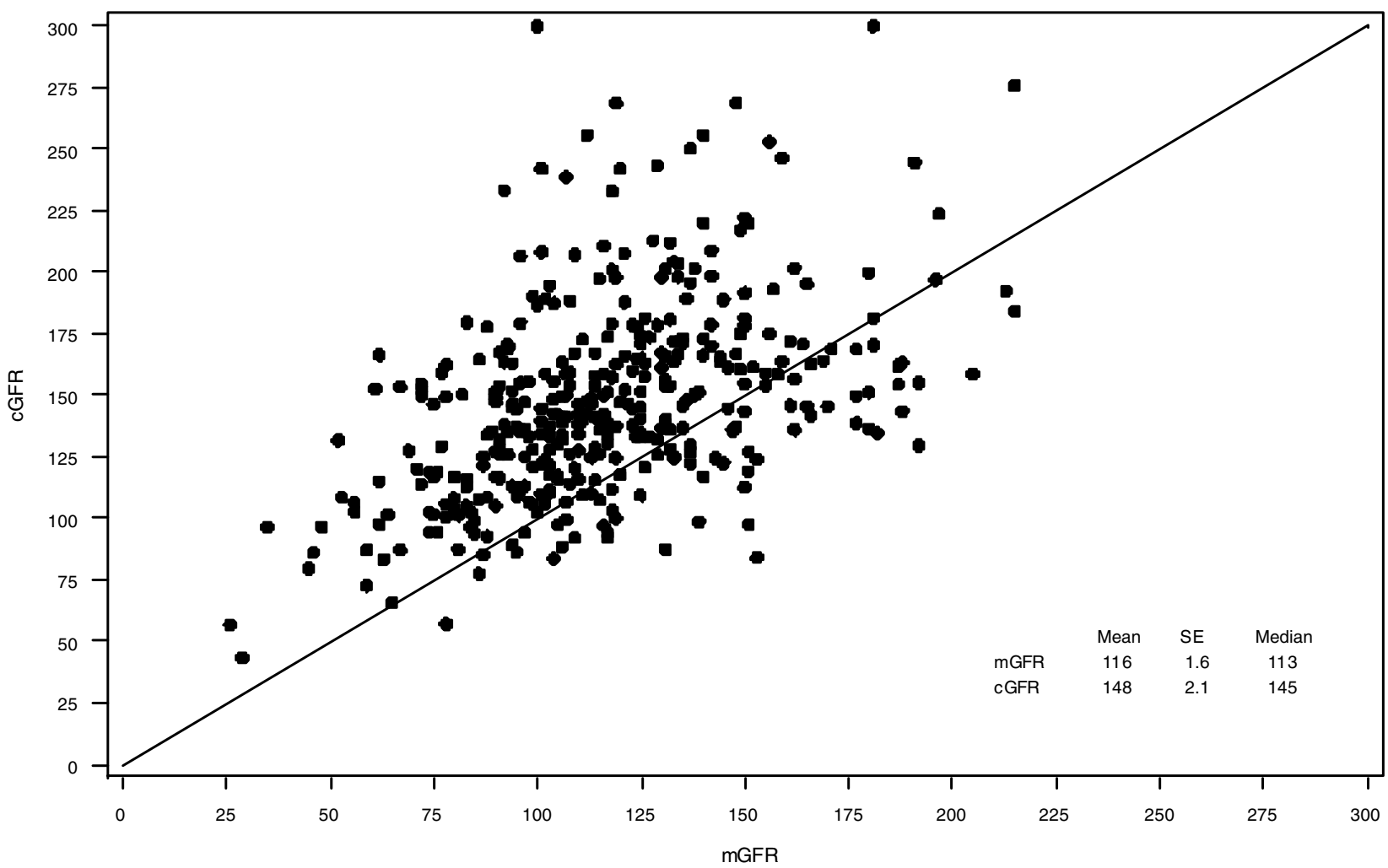

Figure 4: mGFR and cGFR at follow-up. 
SPLIT Posttransplant Kidney Function

Table 2: Univariate analysis comparing patients with and without post-LT renal dysfunction $(N=327)$

\begin{tabular}{|c|c|c|c|}
\hline Variable & $m G F R<90(n=54)$ & $m G F R \geq 90(n=273)$ & p-Value \\
\hline & $16.5 \%$ & $83.5 \%$ & \\
\hline Transplant center (\%) & & & 0.0044 \\
\hline Center A & 12 & 88 & \\
\hline Center B & 13.5 & 86.5 & \\
\hline Center C & 39.1 & 60.9 & \\
\hline Center D & 16 & 84 & \\
\hline Center H & 8.3 & 91.7 & \\
\hline Others (centers $\mathrm{E}, \mathrm{F}, \mathrm{G}, \mathrm{I}$ ) & 28.8 & 73.2 & \\
\hline Age at LT (mean $\pm \mathrm{SD}$ ) & $6.13( \pm 4.97)$ & $3.57( \pm 3.92)$ & 0.0012 \\
\hline $\operatorname{Sex}(\%)$ & & & 0.1430 \\
\hline Male & 19.5 & 80.5 & \\
\hline Female & 13.5 & 86.5 & \\
\hline Race (\%) & & & 0.1171 \\
\hline White & 19.2 & 80.8 & \\
\hline Black & 5.9 & 94.1 & \\
\hline Hispanic & 14.3 & 85.7 & \\
\hline Other & 7.1 & 92.9 & \\
\hline Primary diagnosis (\%) & & & 0.0228 \\
\hline Biliary atresia & 10.5 & 89.5 & \\
\hline Chronic cholestatic liver disease & 31.7 & 68.3 & \\
\hline Fulminant liver failure & 13.5 & 86.577 .1 & \\
\hline Metabolic liver disease & 22.9 & 85.7 & \\
\hline Cryptogenic cirrhosis & 14.3 & 79.4 & \\
\hline Other & 20.6 & & \\
\hline Patient status at LT (\%) & & & 0.6269 \\
\hline $\mathrm{ICU}$ & 20.7 & 79.3 & \\
\hline Hospitalized, not in ICU & 14.8 & 85.2 & \\
\hline Not hospitalized & 15.9 & 84.1 & \\
\hline cGFR at LT $(\%)$ & & & 0.0131 \\
\hline$<90 \mathrm{~mL} / \mathrm{min} / 1.73 \mathrm{~m}^{2}$ & 29.3 & 70.7 & \\
\hline$\geq 90 \mathrm{~mL} / \mathrm{min} / 1.73 \mathrm{~m}^{2}$ & 14 & 86 & \\
\hline Calculated PELD score at LT (\%) & & & 0.3267 \\
\hline$<0$ & 19 & 81 & \\
\hline $0-10$ & 15.7 & 84.3 & \\
\hline $10-20$ & 8.3 & 91.7 & \\
\hline$\geq 20$ & 16.5 & 83.5 & \\
\hline Height Z-score at LT (\%) & & & 0.1005 \\
\hline Above 2 SD (normal) & 13.9 & 86.1 & \\
\hline Below 2 SD (impaired) & 21.2 & 78.8 & \\
\hline Weight Z-score at LT (\%) & & & 0.6808 \\
\hline Above 2 SD (normal) & 15.7 & 84.3 & \\
\hline Below 2 SD (impaired) & 17.6 & 82.4 & \\
\hline Year of 1 st LT (\%) & & & 0.4699 \\
\hline $1995-2000$ & 18.4 & 81.6 & \\
\hline $2001-2006$ & 15.3 & 84.7 & \\
\hline Immunosuppression at day 30 post-LT (\%) & & & 0.0182 \\
\hline Cyclosporine & 26.2 & 73.8 & \\
\hline Tacrolimus & 13.8 & 86.2 & \\
\hline Kidney complications in first 30 days post-LT (\%) & 41.2 & 58.8 & 0.0049 \\
\hline No kidney complications (\%) & 15.2 & 84.8 & \\
\hline Vascular complications in first 30 days post-LT (\%) & 25.5 & 74.5 & 0.0602 \\
\hline No vascular complications (\%) & 14.9 & 85.1 & \\
\hline Hepatic artery thrombosis in first 30 days post-LT (\%) & 29.4 & 70.6 & 0.1413 \\
\hline No hepatic artery thrombosis (\%) & 15.8 & 84.2 & \\
\hline Retransplanted in first 30 days post-LT (\%) & 25 & 75 & 0.4199 \\
\hline Not retransplanted in first 30 days (\%) & 16.2 & 83.8 & \\
\hline Days hospitalized in first 30 days post-LT & & & 0.1444 \\
\hline$<30$ days & 14.6 & 85.4 & \\
\hline 30 days & 21.4 & 78.6 & \\
\hline
\end{tabular}

Continued 


\section{Campbell et al.}

Table 2: Continued

\begin{tabular}{|c|c|c|c|}
\hline Variable & $m G F R<90(n=54)$ & $m G F R \geq 90(n=273)$ & $\mathrm{p}$-Value \\
\hline cGFR at 12 months post-LT (\%) & & & 0.0041 \\
\hline$<90 \mathrm{~mL} / \mathrm{min} / 1.73 \mathrm{~m}^{2}$ & 33.3 & 66.7 & \\
\hline$\geq 90 \mathrm{~mL} / \mathrm{min} / 1.73 \mathrm{~m}^{2}$ & 13.9 & 86.1 & \\
\hline Immuno-suppression at 12 months post-LT (\%) & & & 0.0071 \\
\hline Cyclosporine & 29.4 & 70.6 & \\
\hline Tacrolimus & 14.1 & 85.9 & \\
\hline Number of rejections in first 12 months post-LT & & & 0.2461 \\
\hline (\%) & 20.1 & 79.9 & \\
\hline None & 14.3 & 85.7 & \\
\hline 1 & 11.5 & 88.5 & \\
\hline 2 or more & & & \\
\hline Height Z-score at 12 months post-LT (\%) & & & 0.0004 \\
\hline Above 2 SD (normal) & 12 & 88 & \\
\hline Below 2 SD (impaired) & 29.3 & 70.7 & \\
\hline Weight Z-score at 12 months post-LT (\%) & & & 0.0236 \\
\hline Above 2 SD (normal) & 14.1 & 85.9 & \\
\hline Below 2 SD (impaired) & 27.1 & 72.9 & \\
\hline Age at mGFR follow-up (\%) & & & $<0.0001$ \\
\hline$<13$ years & 11.4 & 88.6 & \\
\hline $13+$ years & 31.7 & 68.3 & \\
\hline Number of transplants (\%) & & & 0.2060 \\
\hline 1 & 15.7 & 84.3 & \\
\hline 2 or 3 & 25 & 75 & \\
\hline Time since transplant-years (mean \pm SD) & $6.26( \pm 3.41)$ & $5.93( \pm 2.75)$ & 0.7828 \\
\hline
\end{tabular}

center, older age at LT, cGFR $<90 \mathrm{~mL} / \mathrm{min} / 1.73 \mathrm{~m}^{2}$ at $\mathrm{LT}$, and height Z-score more than 2 standard deviations below normal at 12 months post-LT.

Since transplant center and primary immunosuppression were highly correlated (uncertainty coefficient of 0.41 ), a secondary model was developed to control for centerspecific effects. This model assumes that each center has a random effect that reflects the possibility of different baseline risks for patients at different centers. In this model (Table 4) age at LT, cGFR at LT and height Z-score at 12 months post-LT remain significant, but immunosuppression at 12 months post-LT emerges as a factor independently associated with mGFR.

\section{Discussion}

In this multicenter, cross-sectional study, we found that $17.6 \%$ of patients $\geq 1$ year post-LT had a mGFR <
$90 \mathrm{~mL} / \mathrm{min} / 1.73 \mathrm{~m}^{2}$, corresponding to stage 2 or higher chronic kidney disease. Risk for kidney dysfunction was directly associated with age at transplant and with a cGFR $<90 \mathrm{~mL} / \mathrm{min} / 1.73 \mathrm{~m}^{2}$ at LT, both of which have been described previously, primarily in adult populations $(1,10,11,33-35)$.

By virtue of the cross-sectional design of our study, it was impossible to define the occurrence of kidney dysfunction over time; instead we have only a snapshot of this complication in our population. In addition, since we relied on a single measure of GFR to classify each patient, it is possible that patients may have been misclassified. Although measured GFR is considered the 'gold-standard' for assessment of kidney function, assay variability and physiologic variability may affect the reproducibility of a single measurement. Given that our study population were stable outpatients undergoing routine, highly protocolized screening, physiologic variability was likely minimal and, as there

Table 3: Factors associated with post-LT renal dysfunction by logistic regression modeling $(n=289)$

\begin{tabular}{|c|c|c|c|c|c|}
\hline Variable & Comparison group & Reference group & Odds ratio & $95 \% \mathrm{Cl}$ & p-Value \\
\hline \multirow[t]{6}{*}{ Transplant center } & B & \multirow{6}{*}{$A$} & 1.59 & $0.49-5.23$ & 0.4433 \\
\hline & C & & 7.58 & $2.34-24.55$ & 0.0007 \\
\hline & $\mathrm{D}$ & & 2.61 & $0.60-11.31$ & 0.2007 \\
\hline & $\mathrm{H}$ & & 1.00 & $0.26-3.93$ & 0.9959 \\
\hline & Other $(E, F, G, I)$ & & 3.58 & $1.35-9.54$ & 0.0106 \\
\hline & Overall & & & & 0.0083 \\
\hline Age at LT & \multicolumn{2}{|c|}{ continuous } & 1.24 & $1.14-1.35$ & $<0.0001$ \\
\hline cGFR at LT & $<90 \mathrm{~mL} / \mathrm{min} / 1.73 \mathrm{~m}^{2}$ & $\geq 90 \mathrm{~mL} / \mathrm{min} / 1.73 \mathrm{~m}^{2}$ & 3.61 & $1.40-9.31$ & 0.0080 \\
\hline Height Z-score at 12 months post-LT & Below 2 SD (impaired) & Above 2 SD (normal) & 3.98 & $1.82-8.70$ & 0.0005 \\
\hline
\end{tabular}


SPLIT Posttransplant Kidney Function

Table 4: Factors associated with post-LT renal dysfunction by mixed effects modeling with center included as a random effect $(\mathrm{n}=289$ )

\begin{tabular}{|c|c|c|c|c|c|}
\hline Variable & Comparison group & Reference group & Odds ratio & $95 \% \mathrm{Cl}$ & p-Value \\
\hline Immunosuppression at 12 months post-LT & Cyclosporine & Tacrolimus & 2.85 & 1.15 to 7.06 & 0.0238 \\
\hline $\begin{array}{l}\text { Age at LT } \\
\text { cGFR at LT } \\
\text { Height Z-score at } 12 \text { months post-LT }\end{array}$ & $\begin{array}{l}<90 \mathrm{~mL} / \mathrm{min} / 1.73 \mathrm{~m}^{2} \\
\text { Below 2 SD (impaired) }\end{array}$ & $\begin{array}{l}\text { uous } \\
\geq 90 \mathrm{~mL} / \mathrm{min} / 1.73 \mathrm{~m}^{2} \\
\text { Above } 2 \mathrm{SD} \text { (normal) }\end{array}$ & $\begin{array}{l}1.23 \\
3.57 \\
3.85\end{array}$ & $\begin{array}{l}1.14 \text { to } 1.35 \\
1.39 \text { to } 9.11 \\
1.79 \text { to } 8.27\end{array}$ & $\begin{array}{r}<0.0001 \\
0.0080 \\
0.0006\end{array}$ \\
\hline
\end{tabular}

is no reason to suspect a systematic bias in the assays employed, variability on this level is likely to have been random.

Similar to our results, Arora-Gupta et al. found that younger age at LT was associated with better long-term kidney function in pediatric patients (20). In their population, children less than 1 year of age at the time of LT experienced the same early decrease in kidney function as did older children, but had a greater subsequent and sustained improvement in cGFR (20). The protective effect of younger age may be related to increased plasticity and/or regenerative potential of the kidney. There is evidence to support this type of age-dependent risk for kidney ischemia/reperfusion injury, in which younger animals are more resistant and recover more rapidly following an ischemic insult $(36,37)$. In addition, ontogenic differences in calcineurin inhibitor absorption and metabolism may contribute to different patterns of calcineurin inhibitor exposure in younger patients (38). While developmental differences in hepatic cytochrome p450 activity may not be relevant in a liver transplant population, there is emerging evidence of an age-dependent effect of genetic polymorphisms in the pathway of calcineurin inhibitor absorption on the oral bioavailability, and thus systemic exposure, of these drugs $(39,40)$. This may explain the need for TID rather than BID dosing of cyclosporine that has been described in young pediatric liver and kidney transplant recipients $(25,41,42)$.

Both pretransplant serum creatinine and cGFR have been identified as risk factors for later kidney dysfunction in adult populations. Ojo et al. found that pretransplant cGFR was inversely related to the relative risk of posttransplant chronic kidney disease, with even a mild decrease in cGFR (60-89 $\left.\mathrm{mL} / \mathrm{min} / 1.73 \mathrm{~m}^{2}\right)$ associated with a relative risk of chronic kidney disease of 1.54 (10). Pawarode et al. identified pretransplant serum creatinine as a risk for posttransplant kidney dysfunction, defined as a decrease in median GFR more than $30 \mathrm{~mL} / \mathrm{min} / 1.73 \mathrm{~m}^{2}$ sustained for at least 6 months (33). Ours is the first study to find this association in pediatric $L T$ recipients and, like the Ojo study, our data indicate that even a mild decrease in pretransplant cGFR is associated with an increased odds of posttransplant kidney dysfunction. It is important to note that the majority of patients with a cGFR $<90 \mathrm{~mL} / \mathrm{min} / 1.73 \mathrm{~m}^{2}$ at $\mathrm{LT}$ and a $\mathrm{mGFR}>90 \mathrm{~mL} / \mathrm{min} / 1.73 \mathrm{~m}^{2}$ at follow-up (24 of 31) were less than 2 years of age at the time of LT. A $\mathrm{GFR}<90 \mathrm{~mL} / \mathrm{min} / 1.73 \mathrm{~m}^{2}$ is normal in this age range, and the subsequent increase in GFR likely represents normal age-related physiologic changes. In addition, although 80\% of the patients with kidney dysfunction at follow-up had a normal cGFR at the time of LT, the propensity of cGFR to overestimate kidney function (Figure 4) makes it impossible to define these patients as true 'de novo' posttransplant kidney dysfunction. Therefore, while cGFR at the time of $\mathrm{LT}$ is a powerful risk factor in our analysis, its sensitivity and specificity at predicting later kidney function in a pediatric liver transplant population is poor.

This study also found a significant association between height Z-score at 12 months posttransplant and later kidney dysfunction. In this setting, height Z-score might serve as an early marker for more severe kidney dysfunction with secondary growth failure. However, there was no correlation between height Z-score and cGFR at 12 months post$\mathrm{LT}$. In addition, a recent analysis by Alonso et al. of linear growth patterns post-LT using the SPLIT database found no independent relationship between CGFR at 12 months post-LT and height Z-score at 24 months post-LT (43). Alternatively, height may serve as a marker for a particular diagnosis. In our population height Z-score correlated with primary diagnosis, with the lowest height Z-score at 12 months in the group of patients with 'other cholestatic' disorders (data not shown). Thus, low height Z-score may be a surrogate marker for a particular type of pediatric cholestatic disorder associated with an increased risk of posttransplant kidney dysfunction. Alagille syndrome in particular emerges as a likely candidate due to the association of the syndrome with both growth retardation and structural and/or functional kidney disease (44). In an attempt to clarify the relationship between kidney function and diagnosis, we re-analyzed the data stratifying diagnosis by known risk of primary kidney involvement (high risk group: Alagille syndrome, alpha-1-antitrypsin deficiency, Wilson's disease, glycogen storage disease, tyrosinemia and congenital hepatic fibrosis), as did Harambat et al. in their 2008 paper (28). Interestingly, using this classification primary diagnosis was not significant in the univariate analysis ( $p$-value 0.2888). Given the small number of patients with Alagille syndrome in the cohort $(n=14)$ it was not possible to include it as an individual diagnostic category.

The emergence of transplant center as an independent factor in the multivariate analysis is intriguing, as a center effect has not previously been described in studies focusing on post-LT outcomes. In this analysis, center effect was associated with posttransplant kidney function 


\section{Campbell et al.}

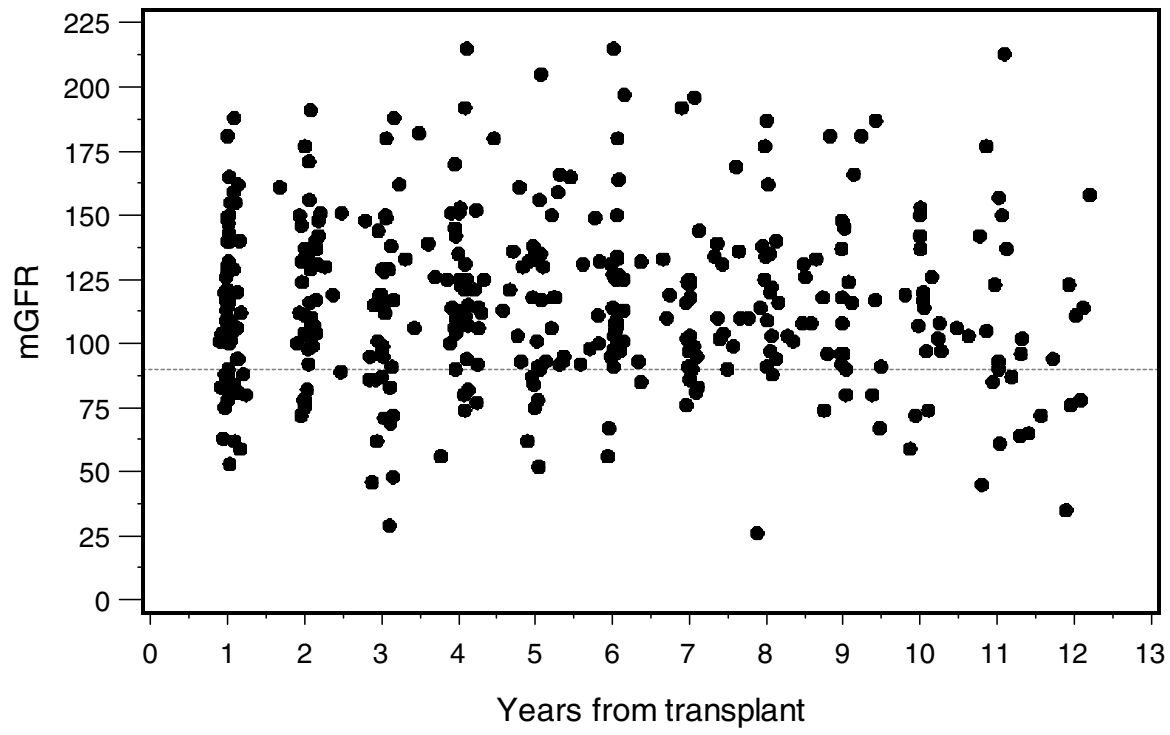

Figure 5: Distribution of $\mathrm{mGFR}$ at follow-up by time since transplant. independent of other factors considered; however, when a random mixed effects model was employed to control for center effect, primary immunosuppression emerges as an independent risk factor. While an increased risk of kidney dysfunction with cyclosporine has frequently been hypothesized, a true difference between cyclosporine and tacrolimus may be missed in single center studies, in which the majority of patients receive the same calcineurin inhibitor based on center standard. In addition, center standards tend to change over time, such that use of cyclosporine immunosuppression frequently correlates with transplant era, further complicating any relationship between immunosuppressive agent and clinical outcome $(22,25,28)$. Our results are in keeping with the multicenter study by Ojo and colleagues, in which cyclosporine immunosuppression was found to be a risk factor for chronic kidney disease in LT patients specifically (10). Although the use of cyclosporine continues to decrease in both pediatric and adult LT programs, with $<10 \%$ of patients transplanted in 2006 receiving cyclosporine as primary immunosuppression, this is an important factor in that it confers significant risk and is easily modifiable $(45,46)$.

The ability to discern differences in kidney risk between cyclosporine and tacrolimus is further confounded by the relationship between immunosuppression regimen, kidney function and time since transplant, such that time since transplant correlates with both cyclosporine use and kidney function. A major finding of this work is the lack of significance of time since transplant (Figure 5), at least within the follow-up period included in this study (up to 11 years posttransplant).

There are multiple reasons why the baseline risk for kidney dysfunction, and the impact of additional factors, might differ across transplant centers. Firstly, patient selection bias might contribute to a perceived center effect. Although all involved centers were obtaining mGFRs routinely as a screening test across their pediatric LT population, the percentage of eligible patients tested at each center was variable, ranging from 42 to $92 \%$. The reasons for this are unclear, although percent enrollment did not correlate with either center volume or incidence of kidney dysfunction (data not shown). Furthermore, there were discernable differences between those patients who had GFRs measured and those who did not (sex, race, transplant era), indicating a potential selection bias at one or more centers. Other potential components of center effect include variables examined in our study (primary diagnosis, time since transplant, etc.) but whose significance may have been lost as a consequence of study design. In our focus on identifying factors associated with kidney function for a heterogeneous population of pediatric LT recipients, interactions among demographic and clinical risk factors that vary from center to center might be undetectable in the large cohort, a limitation of the reductionist multivariate analysis. This is supported by previous reports on post-LT kidney dysfunction from three of the SPLIT centers involved in the current study $(22,23,25)$. While there was some overlap in findings, several risk factors identified in each of these single-center analyses were different compared not only to one another, but also to the current analysis. This is likely related, in part, to differences in the overall patient populations between centers. Unfortunately, given the modest number of patients contributed by most of the centers involved in the current study, an in-depth analysis of potential differences in patient populations was not feasible.

Center effect might also include important variables which we were unable to capture in this analysis. Center-specific practices, such as use of antihypertensive agents and target immunosuppression ranges, were beyond the scope of this study, as were quantitative measures of immunosuppression exposure for individual patients. Similarly, since 
mGFRs were included from patients at variable times post$L T$, it is possible that immunosuppression was altered in response to earlier GFR measurements leading to subsequent improvement in kidney function. The use of decreased calcineurin inhibitor dosing in combination with mycophenolate mofetil is one of several effective kidneysparing strategies commonly used in clinical practice but not captured in this data set (47-50). These potential differences among center populations and practices leave the opportunity for comparative effectiveness studies to identify best clinical strategies for specific subgroups of patients.

In spite of these limitations, the availability of rich clinical data, prospectively captured in the multicenter SPLIT consortia database, allowed us the opportunity to include a large number of variables that would have been difficult to capture, and potentially unreliable, within the confines of a retrospective analysis. This allowed us to identify a set of risk factors applicable across all participating centers, and likely applicable across the pediatric LT population as a whole. Another strength of this study is the use of measured rather than calculated GFR to assess kidney function; ours is the first multicenter study in either adults or children to employ this measure. Accurate and easy assessment of kidney function remains a challenge in pediatric patients with end-stage liver disease and following LT (29). Although radionuclide GFR provides the most accurate measure of kidney function available clinically, these procedures are expensive, time consuming, require specialized training and may not be readily available for smaller children in predominantly adult institutions. More reliable, less invasive estimations such as cystatin C-based equations may offer hope to the bedside clinician. Cystatin $C$ is a widely expressed protein, the serum level of which is not affected by height, sex or body composition. While the data in pediatric transplant recipients are limited to a single study, cystatin $C$ seems to be a better marker for assessing kidney dysfunction than serum creatinine and, if validated in a larger pediatric liver transplant population, may be an ideal substitute for radionuclide GFRs (51). Until that time, mGFR remains the most appropriate kidney outcome to assess in the context of a clinical study. For centers in which mGFR is not routinely employed for population screening, the findings of this study may help direct targeted testing of high risk patients.

Improvements in patient and graft survival following pediatric LT have left us with a different challenge: maintaining allograft function while minimizing the long-term immune and nonimmune complications related to immunosuppressive therapy. Kidney dysfunction and the potential for end-stage kidney disease are significant risks for young transplant patients. This study finds a number of common factors (immunosuppressive agent, age at transplant, cGFR at transplant, growth failure) associated with posttransplant kidney dysfunction, and paves the way for a spectrum of future investigations targeted toward im- proving care standards and addressing gaps in knowledge regarding this complication. These results can be used to risk-stratify patients prior to the onset of kidney dysfunction, and to test novel interventional therapies in high-risk groups. This study also identifies the presence of centerspecific risk factors for posttransplant kidney dysfunction. Further elucidation of the components of this center effect will require ongoing collaboration among pediatric transplant centers and comparative effectiveness research to identify and share the best strategies for preventing kidney compromise following pediatric LT.

The authors of this manuscript have no conflicts of interest to disclose as described by the American Journal of Transplantation.

\section{References}

1. Fisher NC, Nightingale PG, Gunson BK, Lipkin GW, Neuberger JM. Chronic renal failure following liver transplantation: A retrospective analysis. Transplantation 1998; 66: 59-66.

2. Tsimaratos $M$, Viard $L$, Kreitmann $B$ et al. Kidney function in cyclosporine-treated paediatric pulmonary transplant recipients. Transplantation 2000; 69: 2055-2059.

3. Platz KP, Mueller AR, Blumhardt G et al. Nephrotoxicity following orthotopic liver transplantation. A comparison between cyclosporine and FK506. Transplantation 1994; 58: 170-178.

4. Gonwa TA, Poplawski SC, Husberg BS, Nery JR, Klintmalm GB. Cyclosporine nephrotoxicity in orthotopic liver transplantation. Transplant Proc 1988; 20(3 Suppl 3):401-404.

5. Wheatley HC, Datzman M, Williams JW, Miles DE, Hatch FE. Long-term effects of cyclosporine on renal function in liver transplant recipients. Transplantation 1987; 43: 641-647.

6. Devineni R, McKenzie N, Keown P, Kostuk W, Stiller C, Silver M. Cyclosporine in cardiac transplantation. Can J Surg 1984; 27: 252-254.

7. Myers BD, Ross J, Newton L, Luetscher J, Perlroth M. Cyclosporine-associated chronic nephropathy. N Engl J Med 1984; 311: 699-705.

8. Gratwohl A, Speck B, Wenk M,et al. Cyclosporine in human bone marrow transplantation. Serum concentration, graft-versus-host disease, and nephrotoxicity. Transplantation 1983; 36: 40-44.

9. Powell-Jackson PR, Young B, Calne RY, Williams R. Nephrotoxicity of parenterally administered cyclosporine after orthotopic liver transplantation. Transplantation 1983; 36: 505-508.

10. Ojo AO, Held PJ, Port FK et al. Chronic renal failure after transplantation of a nonrenal organ. N Engl J Med 2003; 349: 931940

11. Gonwa TA, Mai ML, Melton LB et al. End-stage renal disease (ESRD) after orthotopic liver transplantation (OLTX) using calcineurin-based immunotherapy: Risk of development and treatment. Transplantation 2001; 72: 1934-1939.

12. Sarwal M, Pascual J. Immunosuppression minimization in pediatric transplantation. Am J Transplant 2007; 7: 2227-2235.

13. McDiarmid SV. Renal function in pediatric liver transplant patients. Kidney Int Suppl 1996; 53: S77-S84.

14. Bucuvalas JC, Campbell KM, Cole CR, Guthery SL. Outcomes after liver transplantation: Keep the end in mind. J Pediatr Gastro enterol Nutr 2006; 43(Suppl 1): S41-S48.

15. Lane PH. Puberty and chronic kidney disease. Adv Chronic Kidney Dis 2005 ; 12 : $372-377$ 


\section{Campbell et al.}

16. Lane PH, Snelling DM, Hollman A, Langer WJ. Puberty permits increased expression of renal transforming growth factorbeta1 in experimental diabetes. Pediatr Nephrol 2001; 16: 10331039.

17. Langer WJ, Devish K, Carmines PK, Lane PH. Prepubertal onset of diabetes prevents expression of renal cortical connective tissue growth factor. Pediatr Nephrol 2008; 23: 275-283.

18. Lane PH. Diabetic kidney disease: Impact of puberty. Am J Physiol Renal Physiol 2002; 283: F589-600.

19. McDiarmid SV, Ettenger RB, Fine RN, Busuttil RW, Ament ME. Serial decrease in glomerular filtration rate in long-term pediatric liver transplantation survivors treated with cyclosporine. Transplantation 1989; 47: 314-318.

20. Arora-Gupta N, Davies P, McKiernan P, Kelly DA. The effect of long-term calcineurin inhibitor therapy on renal function in children after liver transplantation. Pediatr Transplant 2004; 8: 145150.

21. Bartosh SM, Alonso EM, Whitington PF. Renal outcomes in pediatric liver transplantation. Clin Transplant 1997; 11 (5 Pt 1):354-360.

22. Campbell KM, Yazigi N, Ryckman FC et al. High prevalence of renal dysfunction in long-term survivors after pediatric liver transplantation. J Pediatr 2006; 148: 475-480.

23. Avitzur $Y$, De Luca $E$, Cantos $M$ et al. Health status ten years after pediatric liver transplantation-looking beyond the graft. Transplantation 2004; 78: 566-573.

24. Berg UB, Ericzon BG, Nemeth A. Renal function before and long after liver transplantation in children. Transplantation 2001; 72: 631637.

25. Herzog D, Martin S, Turpin S, Alvarez F. Normal glomerular filtration rate in long-term follow-up of children after orthotopic liver transplantation. Transplantation 2006; 81: 672-677.

26. Mention K, Lahoche-Manucci A, Bonnevalle M et al. Renal function outcome in pediatric liver transplant recipients. Pediatr Transplant 2005; 9: 201-207.

27. Andrews WA, Arant BS, Fyock B, Gray S, Schlatter MG, Conlin C. The effect of cyclosporine $A$ on long-term renal function in pediatric liver transplant recipients. Transplant Proc 1991; 23: 1452-1453.

28. Harambat J, Ranchin B, Dubourg $L$ et al. Renal function in pediatric liver transplantation: A long-term follow-up study. Transplantation 2008; 86: 1028-1034.

29. Filler G, Sharma AP. How to monitor renal function in pediatric solid organ transplant recipients. Pediatr Transplant 2008; 12: 393-401.

30. Levey AS, Coresh J, Balk E et al. National Kidney Foundation practice guidelines for chronic kidney disease: Evaluation, classification, and stratification. Ann Intern Med 2003; 139: 137-147.

31. Schwartz GJ, Haycock GB, Edelmann CM, Jr., Spitzer A. A simple estimate of glomerular filtration rate in children derived from body length and plasma creatinine. Pediatrics 1976; 58: 259-263.

32. Kuczmarski R, Ogden C, Guo S et al. 2000 CDC growth charts for the United States: Methods and development. 2002.

33. Pawarode A, Fine DM, Thuluvath PJ. Independent risk factors and natural history of renal dysfunction in liver transplant recipients. Liver Transpl 2003; 9: 741-747.

34. Sharma P, Welch K, Eikstadt R, Marrero JA, Fontana RJ, Lok AS. Renal outcomes after liver transplantation in the model for endstage liver disease era. Liver Transpl 2009; 15: 1142-1148.
35. Burra P, Senzolo M, Masier A et al. Factors influencing renal function after liver transplantation. Results from the MOST, an international observational study. Dig Liver Dis 2009; 41: 350-356.

36. Fernandez M, Medina A, Carbajo E et al. Prepubertal rats are more resistant to ischemic renal injury and recover more rapidly than adult rats. Exp Nephrol 2000; 8: 299-303.

37. Shimizu MH, Araujo M, Borges SM, de Tolosa EM, Seguro AC. Influence of age and vitamin $\mathrm{E}$ on post-ischemic acute renal failure. Exp Gerontol 2004; 39: 825-830.

38. Kearns GL, Abdel-Rahman SM, Alander SW, Blowey DL, Leeder JS, Kauffman RE. Developmental pharmacology-drug disposition, action, and therapy in infants and children. N Engl J Med 2003; 349: 1157-1167.

39. Fanta S, Niemi M, Jonsson S et al. Pharmacogenetics of cyclosporine in children suggests an age-dependent influence of ABCB1 polymorphisms. Pharmacogenet Genomics 2008; 18: 7790.

40. Fukudo M, Yano I, Yoshimura A et al. Impact of MDR1 and CYP3A5 on the oral clearance of tacrolimus and tacrolimus-related renal dysfunction in adult living-donor liver transplant patients. Pharmacogenet Genomics 2008; 18: 413-423.

41. Filler G, de Barros VR, Jagger JE, Christians U. Cyclosporin twice or three times daily dosing in pediatric transplant patients-it is not the same! Pediatr Transplant 2006; 10: 953-956.

42. Cooney GF, Habucky K, Hoppu K. Cyclosporin pharmacokinetics in paediatric transplant recipients. Clin Pharmacokinet 1997; 32: 481-495.

43. Alonso EM, Shepherd R, Martz KL, Yin W, Anand R. Linear growth patterns in prepubertal children following liver transplantation. Am J Transplant 2009; 9: 1389-1397.

44. Emerick KM, Rand EB, Goldmuntz E, Krantz ID, Spinner NB, Piccoli DA. Features of Alagille syndrome in 92 patients: Frequency and relation to prognosis. Hepatology 1999; 29: 822-829.

45. Health Resources and Services Administration, Healthcare Systems Bureau, Division of Transplantation Annual Report of the U.S. Organ Procurement and Transplantation Network and the Scientific Registry of Transplant Recipients: Transplant Data 1997-2006. Rockville, MD; 2007.

46. Studies of Pediatric Liver Transplantation 2007 Annual Report. Rockville, Maryland: Emmes; 2007.

47. Beckebaum S, Klein CG, Sotiropoulos GC et al. Combined mycophenolate mofetil and minimal dose calcineurin inhibitor therapy in liver transplant patients: Clinical results of a prospective randomized study. Transplant Proc 2009; 41: 2567-2569.

48. Dell-Olio D, Kelly DA. Calcineurin inhibitor minimization in pediatric liver allograft recipients. Pediatr Transplant 2009; 13: 670-681.

49. Evans HM, McKiernan PJ, Kelly DA. Mycophenolate mofetil for renal dysfunction after pediatric liver transplantation. Transplantation 2005; 79: 1575-1580.

50. Tredger JM, Brown NW, Dhawan A. Calcineurin inhibitor sparing in paediatric solid organ transplantation: Managing the efficacy/toxicity conundrum. Drugs 2008; 68: 1385-1414.

51. Samyn M, Cheeseman P, Bevis $L$ et al. Cystatin $C$, an easy and reliable marker for assessment of renal dysfunction in children with liver disease and after liver transplantation. Liver Transpl 2005; 11: 344-349. 